\title{
Oralidad y orfandad en la escritura de Juan Rulfo
}

\section{Orality and orphanhood in Juan Rulfo's writing}

Fabio Jurado Valencia*

Recibido: 23 de junio de 2011

Aprobado: 8 de noviembre de 2011

\section{Resumen}

El artículo se propone aportar elementos conceptuales en torno a la oralidad y sus posibles convergencias en la escritura literaria, para contribuir a resolver una problemática: la comprensión del remodelamiento de la oralidad a través de la escritura literaria. Oralidad y escritura se enhebran en el proyecto narrativo de Juan Rulfo. Esta relación triádica entre oralidad, escritura y orfandad es reveladora de las cosmovisiones latinoamericanas. El valor estético de la obra de Rulfo se apuntala en la fuerza verosímil que produce la escritura al hacernos sentir la oralidad en un aquí-ahora del contador de historias. Este valor deviene también de la competencia discursiva con la cual, a la vez que se redescubre la idiosincrasia de las comunidades rurales, nos acerca a los universos de las culturas periféricas del mundo. La orfandad no es solo material (la pobreza y la impotencia de hombres y mujeres del campo) sino también y sobre todo espiritual-cultural. Los silencios y los mutismos son los signos de la frustración en los personajes de Rulfo y todo silencio es habla interior asintáctica; esta habla nos llega a través de la escritura, luego se trata de una escritura oralizada 0 de una oralidad escriturada.

Palabras clave: oralidad, escritura, orfandad, monodiálogo, narrador, narratario.

\section{Abstract}

Orality and writing constitute a mix in Juan Rulfo narrative project. This triadic relationship shows Latin American worldviews. The aesthetic value of Juan Rulfo's work is in the oral force of writing and the feeling of a present storyteller. Furthermore, Rulfo's discursive competence not just shows us the idiosyncrasy of rural communities, it also bring us closer to outlying cultures. Orphanhood is not just a material question (the poverty and impotence of rural people), it's also a cultural and spiritual question. Silences are the signs of frustration in Juan Rulfo's characters. But every silence is an interior speech that arrives with writing, an oral writing or a written orality.

Key words: orality, writing, orphanhood, interior speech, narrator, narrate.

Doctor en literatura. Profesor del Departamento de Literatura e Instituto de Investigación en Educación, Universidad Nacional de Colombia. Correo: fdjuradov@unal.edu.co. 


\section{Introducción ${ }^{1}$}

Con las tesis de Maestría y, posteriormente, con la de Doctorado en Literatura, presentadas en la Universidad Nacional Autónoma de México, hemos sostenido una línea de trabajo que tiene como horizonte proporcionar algunos elementos conceptuales en torno a la oralidad y sus posibles convergencias en la escritura literaria, siempre con la preocupación de enlazar estas reflexiones con la formación de lectores críticos desde los contextos educativos; así, entonces, en distintos proyectos de investigación en el ámbito de la educación he asignado un lugar al análisis de obras literarias que como las de Rulfo constituyen signosreveladores de la cosmovisión de las comunidades rurales y, sobre todo, posibilitan comprender el remodelamiento de la oralidad a través de la escritura literaria.

Este trabajo es una continuación de dicha preocupación y busca aportar a una discusión que todavía no se resuelve, pues la caracterización de los procesos de enunciación de los narradores de las obras del escritor mexicano estodavía objeto de investigación, si bien en el año 2012 el trabajo de Françoise Perus (Juan Rulfo, el arte de narrar) abona de manera significativa el terreno de estas indagaciones. En general, el objetivo trazado es mostrar de qué modo la oralidad hace parte de los tonos en los discursos de narradores y personajes de Rulfo y no constituye una transcripción grafofonética de las locuciones de los hablantes de las regiones de la periferia, aunque la escritura haga sentir que escuchamos y no que leemos. Pero, más allá de este propósito, se trata de resaltar los efectos estéticos y éticos de las representaciones literarias de Rulfo, muy propicias para comprender la complejidad del mundo.

\section{El autor y sus materiales orales}

En su juventud, Juan Rulfo es un escalador de montañas y un viajero por las provincias mexicanas. Es un aficionado a la fotografía, y en sus registros visualesse percibirán las geografías de la periferia, sugerentes de las antropologías de la oralidad de las comunidades rurales y de los pequeños pueblos. La experiencia como caminante y viajero le permite asimilar las voces, aprehenderlas, de hombres y mujeres del campo y de los pueblos del centro y noroccidentede México. Conoce, pues, el otro México, el México profundo, aquel México que después de la revolución agraria (1910-1917) y de la revolución cristera (1926-1928) permanecerá en el misterio y en la inequidad. Los conocimientos empíricos del escritor se complementarán con los resultados de sus indagaciones en los archivos de inmigración, primero, y en las lecturas que hará de los cronistas de Indias, después, para asegurar la calidad de un proyecto literario en el que persistiráhasta el final de su vida, en 1986.

La oralidad, reconfigurada en la escritura, en el caso de Rulfo es un asunto de tonos discursivosy de sensaciones sonorasy no de transcripciones grafofonéticas $^{2}$, como se lo propusieron los autores de las lite-

1 Una versión parcial de este trabajo se expuso en el VII Congreso Internacional: Literatura, Memoria e Imaginación de Latinoamérica y el Caribe: "Por los derroteros de la oralidad y la escritura", llevado a cabo en la ciudad de Quito en el año 2011.

2 Víctor Jiménez (2006, p. 356) destaca al respecto el caso de Los de abajo, de Azuela, quien "al hacer hablar a Camila, campesina ignorante, sólo puede poner en su boca palabras como ‘iAnde, pos yo creiba que el aguardiente nomás pal cólico era güeno!... ¡Ah!... ¿De modo que usté iba a ser dotor?” Abundan los ejemplos en la narrativa de la revolución y del indigenismo: en La venganza de Carlos Mango, de Francisco Rojas González, un personaje dice: "Pos ya que usté siarma, que venga el último, hay que dejar los asientos pa l'amanezca... ¿o quiopina?” (1952, p. 69). También en El ardiente verano, de Mauricio Magdaleno, dice uno de los personajes del cuento "Palo ensebado": "Quesque dice que tiene que venir a reclamarle lo suyo a su güena mercé, amo don Teófilo” (1954, p. 154). 
raturas regionales e indígenas de las décadas de 1920 a 1950; la dificultad para lograr las percepciones de la oralidad en el texto literario está en cómo lograr los tonos (o la entonación) y los modos particulares de narrar para representar los universos microculturales de una comunidad. Escuchar, saber interpretar las voces en las plazas, sentir las canciones populares y los rezos en aquellas iglesias semiderruidas (como la que es representada en "Luvina") constituye el material fundamental en el trabajo de un poeta que escribe en prosa haciendo sentir el verso.

\section{La oralidad como percepción en la escritura}

Señala Mignolo (1992) que en el caso de la obra de Rulfo se trata de la ficcionalización de la oralidad proyectada en la escritura literaria; tal ficcionalización permite identificar modos de pensar y de creer y se proyecta en comportamientos propios de la ilusión y la impotencia. Pero no es la oralidad con sus sustancias y formas de expresión propias ( $c f r$. Hjelmslev, 1972), sino una escritura en la que se percibe la oralidad. La oralidad se incrusta en el fondo de una escritura que, al ser objeto de interpretación, produce el efecto de ser escuchada y no leída. Por eso, los discursos de los narradores y de los personajes se mimetizan entre sí o se funden; unas y otras voces se fusionan en la prevalencia de unos tonos que hacen sentir la oralidad de quienes conversan y recuerdan, o rememoran sus tragedias (campesinos que habitan en las fronteras de los pequeños pueblos, o en ellos mismos, como en "Acuérdate").

En los cuentos de Rulfo es inevitableel dilema sobre cómo mostrar de manera simultánea las voces interiores, o los soliloquios o "monodiálogos" ( $c f r$. Rama, 1974-1982) de los personajes/narradores, como ocurre en "El hombre" o en "Luvina". Tal propósito es logrado a partir de la lucha del artista con el lenguaje, oral y escrito, visible en los múltiples sig- nos tipográficos del texto: comillas para indicar la voz del perseguidor y comillas y bastardilla para el perseguido, por ejemplo, en "El hombre". Pareciera que Rulfo quisiese ayudar al lector con estos signos tipográficos, como aparecerán también en otros cuentos yen Pedro Páramo; sin embargo, los idiolectos, inherentes a los sociolectos de las comunidades rurales, se perciben de tal forma que dichos signos podrían ser innecesarios: por los universos semánticos sabemos cuándo habla el perseguido y cuándo el perseguidor, o cuándo habla Juan Preciado y cuándo la madre desde los recuerdos de Juan, para el caso de Pedro Páramo: el valor artístico de la obra de Rulfo radica, entre otros, en este alcance.

A través de las voces, autónomas y genuinas, pero también ambiguas o plurales, percibimos que quienes hablan se aferran a la memoria o esta se impone obrando en la conciencia moral de los personajes; es otro aporte de la obra de Rulfo:ingresar literariamente en estos mundos rurales de intensos silencios y de economías verbales para mostrar cómo las construccionesdiscursivas orales de los personajes son suficientes para nombrar sus propias experiencias y a través de ellasposibilitar las representaciones míticas en sus cosmovisiones. No es "la ficcionalización de registros escritos", tan propia de la literatura canónica, "más atenta a las particularidades de la escritura que a las de la voz" (Mignolo, 1992, p. 438), sino la ficcionalización de las voces orales que, por supuesto, solo podemos recibir a través de la escritura. Lienhard (1992) llama etnoficción a esta escritura con la que se representa la oralidad y la cosmovisión de las comunidades periféricas, aspecto que de algún modo se asocia con lo que autores como Rama y Pacheco habían planteado en la década de 1970 alrededor de la transculturación: no setrata de una escritura que se acopla taxativamente con el sistema de la lengua estándar sino de una escritura que produce efectos de oralidad y a la vez representa la simbiosis cultural de las comu- 
nidades de la periferia. Con efectos de oralidad se quiere indicar la experiencia de sensaciones sobre cómo lo leído es escuchado porque alguien les habla a otros. No es propiamente lo oral, tal como es en la vida práctica, sino lo oral percibido literariamentey asumido como necesidad para nombrar los destinos trágicos y los sentimientos de orfandad y de impotencia de hombres y mujeres en un territorio.

La re-lectura de los cuentos y la novela de Rulfo (y cada lectura es siempre diferente, lo cual revela su valor estético y su perennidad) permite colegir que el autor mexicano hubiese preferido que los personajesinteractuarancon sus propias hablas, sin narradores externos, como una manera de comprender estos mundos, aún para el mismo autor ${ }^{3}$; los investigadores en ciencias sociales echan mano de estas estrategias para asegurar sus interpretaciones: dejar que transcurran las voces de sus informantes y develar así las creencias, las representaciones imaginarias y sus saberes; pero en literatura esto es imposible, porque la literatura implica un trabajo con el lenguaje y aquello será siempre un material para procesar literariamente; sin embargo, escritores como Rulfo aprenden de los investigadores y viven la experiencia del investigador (es raro que exista un artista que no investigue); en esta perspectiva fue ilustrativo para Rulfo la obra de Fray Bernardino de Sahagún, a quien estudió y sobre quien escribió:

No es de extrañar pues, que Fray Bernardino se traslade fuera de la ciudad de México y busque en el pueblo de Tepepepulco (hoy Tepeapulco), el sitio más adecuado para iniciar sus indagaciones, haciéndose acompañar de varios de sus alumnos. Auxiliado por éstos, logra reunir a un grupo de ancianos, así como dibujantes o tlacuilos, quienes van trazando sobre el papel e interpretando la narraciónde aquellos viejos supervivientes.
Etnógrafo y lingüista innato, el fraile va guiando la investigación hacia los temas que le parecen primordiales: la cosmogonía y su significado; los hábitos cotidianos; los fenómenos naturales y su relación astronómica. Obtiene así numerosos mitos; la característica real y simbólica de sus deidades y, de igual manera, los cantos poéticos o filosóficos que utilizaban para acercarse a sus dioses (1994, p. 166).

He aquí una de las señales sobre el proyecto estético de Juan Rulfo; puede decirse que esta tarea intelectual de Sahagún, deseoso de desentrañar la cosmovisión de los antiguos nahuas, es asimilada a su modo por Rulfo, quien también se propone escudriñar los mundos de conciencia de los habitantes rurales, sus contemporáneos, y para ello escucha, luego procesa literariamente y modela a un lector que, al leer, interpreta voces; este lector tiene que saber escuchar para saber inferir.

Los cuentos "Diles que no me maten", "La noche que lo dejaron solo", "Paso del Norte", "No oyes ladrar los perros" y "El día del derrumbe" inician con el diálogo entre personajes, es decir, con escenas, en términos de Genette (1972), como ocurre en el teatro o en el guión cinematográfico. Entre estos cuentos, "No oyes ladrar los perros" es el que más intensifica el drama de la conversación, paradójicamente en una relación de tensión entre el padre y el hijo y de manera inversa a la situación representada en "Diles que no me maten": en el primero, el padre lleva en sus espaldas al hijo herido en busca de un médico; el padre insiste en llevarlo mientras que el hijo (un delincuente) se resiste. En el segundo, el padre (homicida de Guadalupe Terreros) pide al hijo que abogue por él dadas las circunstancias de la ejecución que le espera; el padre ruega para que lo salve mientras el hijo insiste

3 Señala José Pascual Buxó respecto a Pedro Páramo "el grave tumulto de unas conciencias a las que el autor finge haber concedido sólo sus servicios de amanuense impasible y fiel” (1992, p. 610). 
en el riesgo de defenderlo: lo matarían a él también y no habría quién cuidara a su mujer y a sus hijos. En el primero, el hijo muere al llegar al pueblo; en el segundo, el padre es fusilado y, hacia el final, el hijo lleva su cadáver de regreso a casa. Estos dos cuentos son reveladores del movimiento circular que caracteriza a las historias que Rulfo recoge en sus tres grandes libros: El llano en Llamas (1953), Pedro Páramo (1955) y El gallo de oro (1959). La circularidad es precisamente un recurso específico de los cuenteros populares: digresiones en el orden de la narración y convergencia entre el inicio y el final de las historias. Los marcadores discursivos de la cuentería popular, o del cuento folclórico, aparecen más directamente en "La herencia de Matilde Arcángel": "En Corazón de María vivían, no hace mucho tiempo, un padre y un hijo conocidos como los Eremites..." (1987, p. 125). Pero el proceso de enunciación va desbordando lo folclórico para dar lugar a la configuración simbólica-literaria ( $c f r$. Jakobson, 1983).

Los deícticos de persona (pronombres personales) son usados por los personajes en los diálogos según las mediaciones sean afectivas, oscilando entre el "tú" y el "usted": "tú" para acentuar la afectividad y la cercanía filial, "usted" para marcar la distancia y la recriminación. "No oyes ladrar los perros", por ejemplo, empieza con la escena:

_ Tú que vas allá arriba, Ignacio, dime si no oyes alguna señal de algo o si ves alguna luz en alguna parte.

- No se ve nada.

- Ya debemos estar cerca.

- Sí, pero no se oye nada.

- Mira bien.

- No se ve nada.

- Pobre de ti, Ignacio (Rulfo, 1987, p. 134).
Aun usando el "tú", aparece como contraste el nombre propio del hijo: Ignacio; la ambivalencia de los afectos entre el padre y el hijo es una constante en los cuentos y en la novela de Rulfo. En este caso, el sentimiento filial estaría más acentuado si el padre dijera: "Tú que vas allá arriba" (hijo). Se comprenderá esta ambivalencia en el discurso recriminatorio posterior, del padre:

- Todo esto que hago no lo hago por usted. Lo hago por su difunta madre. Porque usted fue su hijo. Por eso lo hago. Ella me reconvendría si yo lo hubiera dejado tirado allí, donde lo encontré y no lo hubiera recogido para llevarlo a que lo curen, como estoy haciéndolo. Es ella la que me da ánimos, no usted. Comenzando porque a usted no le debo más que puras dificultades, puras mortificaciones, puras vergüenzas (p. 136).

El discurso oral del padre es explícito en esta escritura depurada, con sintaxis impecable, que desemboca en la agudeza de la declaración de una acusación y una condena; el deíctico "usted" es el paradigma de "tú"; "usted" es dominante en las conversaciones de la vida práctica con sus significados disímiles: se usa para hacer énfasis en el destinatario, es propio de la función apelativa del lenguaje y alcanza su mayor potencia en la exteriorización de los sentimientos frustrados en las relaciones entre padres e hijos: "Porque para mí usted ya no es mi hijo. He maldecido la sangre que usted tiene de mí.... Los enunciados propician la iconicidad de un escenario en el que el padre recrimina y sanciona. Es el complejo de la culpa y el deber filial, tan reiterado en la obra de Rulfo, lo que justifica la actuación en este universo de ambivalencias en el que de antemano el padre ya sabe que su hijo ha de morir: "Pobre de ti, Ignacio", "Peor para ti, Ignacio".

Una especie de transacción entre oralidad y escritura subyace en las literaturas que Ángel Rama (19741982), apoyándose en las reflexiones del cubano 
Fernando Ortiz (1963), denomina transculturales. Se trata de observar un proceso de transformación de la escritura literaria latinoamericana, en la que progresivamente se fue desplazando una "cultura precedente" de escrituras ligadas a la norma y fue emergiendo una "neoculturación" de la escritura y de los lectores. La oralidad se va impregnando de escritura, ya sea porque las comunidades periféricas entran en contacto con "personas de la ciudad" y se propicia el acceso a la escuela o porque los textos impresos van ingresando en estas comunidades, si bien no es lo dominante en las historias de Rulfo, aunque tengan alguna presencia: el discurso estereotipado del gobernador, en "El día del derrumbe", en el que cita a Bernal Díaz del Castillo, es revelador de la formación de una incipiente comunidad letrada, que es objeto de parodia en la escritura de Rulfo. Es este un contraste que el autor pone de relieve: mientras que las voces de los personajes y los narradores de origen humilde son prolijas, las voces en los personajes con roles políticos son artificiosas y ampulosas. También en "Acuérdate" se identifican rasgos de la incipiente comunidad letrada, dado que la historia del personaje está asociada con la escuela y quien narra fue testigo de los eventos ocurridos en su interior.

En la transacción entre oralidad y escritura es notable la presencia de registros propiamente orales, como signo de la preocupación del escritor por representar las imágenes de la memoria devenidas de la experiencia social y, en este caso, del contacto con los hablantes de los pueblos de Jalisco y sus alrededores (Tonaya, Talpa, Colima...). Hay una viva "imaginación eidética" -fijación nítida en la memoria, de cosas y acontecimientos observados, según lo explica José Pascual Buxó (1992)- que se representa y, en consecuencia, se transforma literariamente en los cuentos y en la novela; es lo que hace que en estos textos se instaure el tono del contador oral de historias, se resalte la iconicidad de los ambientes y de las investiduras "rurales" de los personajes. Hacer sentir lo oral en lo escrito es un recurso lingüístico que posibilita destacar las imágenes nucleares de las historias, como en "No oyes ladrar los perros": "Tú que llevas las orejas de fuera, fíjate a ver si no oyes ladrar los perros", "Y desde qué horas que hemos dejado el monte", "Parece que, en lugar de cariño, le hubiéramos retacado el cuerpo de maldad".

La plasticidad del lenguaje es propia también de las interacciones conversacionales en la vida práctica de los habitantes del campo, caracterizadas por la redundancia semántica y ficcionalizadas en la escritura de Rulfo; "las orejas de fuera" y "fíjate a ver" son enunciados que cumplen la función de enfatizar en la comunicación oral; se dice "las orejas de fuera" por oposición a las orejas del padre, quien no puede oír ni ver por la carga que lleva en las espaldas. La dimensión auditiva se sincretiza con la dimensión visual y su mayor condensación se encuentra en el enunciado "fíjate a ver si no oyes ladrar los perros".

Y aunque son pocos, aparecen también enunciados constituidos por palabras que transcriben variantes fonológicas y morfológicas respecto a la lengua estándar:

"A mí me gustan las cosas derechas, y si a ti no te gustan, ahí te lo haiga, porque yo he venido aquí a enderezarlas..." ("La cuesta de las comadres").

"Debía de haberlos tentaleado de uno por uno hasta dar con él..." ("El hombre").

“Qué trairá este hombre?” (“El hombre”).

"Ya lo decía yo que era un juilón" (“El hombre”).

“... y no se le fueran a infestar los mordiscos que el hombre les había dado" ("El hombre").

"Y que dizque yo lo había matado, dijeron los díceres..." ("En la madrugada"). 
"Era de verse cómo se nos atoraban los güevos en el pescuezo con sólo oír el ruido que hacían sus guarniciones..." (“El Llano en llamas”).

"Ahí se lo haiga si me los mata" ("Diles que no me maten").

"Y luego le hizo pelos al burro y se fueron, arrebiatados, de prisa..." ("Diles que no me maten").

“-Eso es, impávido. Bueno, con el argüende de afuera la cosa aquí dentro pareció calmarse" " El día del derrumbe").

"Pero tu abuelo le jerró con venirse aquí" (Pedro Páramo).

Palabras como haiga, tentaleado, trairá, juilón, infestar, díceres, güevos, arrebiatados, argüende, jerró, y tantas otras, son variantes orales de invariantes correspondientes en la lengua castellana; rompen con la norma fonológica y morfológica y hacen parte de la competencia comunicativa oral ${ }^{4}$; pero palabras como estas no son las que configuran la fuerza de la oralidad, es decir, no la determinan por sí solas; es la estructura sintáctica de los enunciados de los narradores y de los personajes, asumidos estos enunciados como totalidad, lo que propicia el efecto de la escucha en los lectores.

Planteó al respecto Ángel Rama que "la contribución original de los transculturadores consiste en la unificación lingüística del texto literario, respondiendo a los principios de unificación artística pero utilizando en substitución de una lengua literaria compuesta y aprendida, la suya propia” (1974-1982, pp. 212-213). Entre los escritores transculturadores Rama ubica a Juan Rulfo, García Márquez, Guimarães Rosa y José
María Arguedas, y resalta en sus obras el espíritu de trabajo hacia el sistema lingüístico para no "imitar desde fuera un habla regional sino elaborarla desde dentro con finalidades literarias" (p. 213):

Desde el momento que no se siente fuera sino dentro de ella, reconociéndolo sin rubor ni disminución, no procura ya copiar con cuidada caligrafía sus irregularidades, sus variaciones frente a una presunta norma académica, que incluso comienza a no percibir como no las percibe el hablante. En cambio, le importará trabajar las posibilidades que le abre su propio comportamiento lingüístico para construir a partir de él una lengua literaria, específica de la creación artística. Si el principio de unificación textual y de lengua literaria puede responder al espíritu racionalizador de la modernidad, la perspectiva lingüística desde donde se lo asume restaura la visión regional que así resulta capaz de englobarlo e imponerle su riqueza plurisémica (p. 213).

Aunque hay cierto ruido, o es disonante, al referirse al "espíritu racionalizador de la modernidad", lo que interesa de este juicio es la búsqueda de un código literario por parte de los escritores frente al agotamiento de los anteriores. Para ello el trabajo con el lenguaje es decisivo. Es decir, no es un propósito voluntario de Rulfo introducir las palabras y los giros populares en los discursos de sus narradores y sus personajes; se trata de locuciones que fluyen en una escritura versátil, que no se cierra sino que integra la percepción de aquellas voces escuchadas, reveladoras de unos mundos que nadie conocía hasta entonces, más allá de los lugares comunes.

4 Al respecto, por la diversidad lingüística -inherente también a la escritura transcultural-, Sergio López Mena publicó un Diccionario de la obra de Juan Rulfo en el que explica que "en varios casos se trata de arcaísmos, de términos que corresponden al siglo XVII y que reflejan el gran aislamiento en que vivieron confinados los pueblos de Jalisco durante mucho tiempo, inclusive hasta mediados del siglo XX" (2007, p. 8). El diccionario en referencia está apoyado a su vez en diccionarios de mexicanismos y, sin duda, constituye una ayuda para los maestros y los estudiantes de la educación secundaria, en la contrastación de estos registros léxicos. 
El sentimiento de la impotencia y la orfandad, las tensiones entre el hijo y el padre, la presión de la cultura en el deber de la venganza, el incesto y el fratricidio, la expoliación, la socarronería religiosa, la tierra abrupta y agreste, la hostilidad del medio, los sincretismos culturales del catolicismo y los remanentes prehispánicos, las fronteras entre los espacios rurales y los pueblos, la imagen de los gobiernos como organismos supuestamente neutrales pueden comprenderse de manera profunda a través de estas singularidades narrativas, porque esos tonos orales afianzan la verosimilitud.

El estilo indirecto constituye otro recurso para evitar la artificialidad de las simulaciones orales en que se cae cuando un autor tiene la pretensión de introducir fielmente en un texto de ficción el habla práctica de los hablantes de una lengua. El estilo indirecto en la narración literaria implica la competencia estética para lograr el efecto de la verosimilitud y la consecuente modelación de un lector que ingresa y coopera con los intersticios del discurso (cfr. Eco, 1980). Rulfo recurre al estilo indirecto, con narradores testigos que enuncian en primera persona (la mayoría) o en tercera persona, apuntando hacia la configuración de la voz colectiva de un grupo o de los habitantes de un pueblo ruralizado. Así, en el cuento "Acuérdate":

"Se dice que tuvo su dinerito, pero se lo acabó en los entierros..."

"Dicen que su tío Fidencio, el del trapiche, le arrimó una paliza que por poco y lo deja parálisis, y que él, de coraje, se fue del pueblo."

"Dicen que antes estuvo en el curato y que hasta le pidió la bendición al padre cura, pero que él no se la dio."

"Dicen que él mismo se amarró la soga en el pescuezo y que hasta escogió el árbol que más le gustaba para que lo ahorcaran."
El narrador enuncia los hechos, no los muestra, comunica lo que sabe y lo que saben los otros y demanda de su interlocutor (quien nunca interviene) el esfuerzo de recordar para nombrar dichos hechos: "Sólo que te falle mucho la memoria, no te has de acordar de eso". En este cuento no aparece el estilo directo (la escena), no hay diálogos pero hay voces: las de los otros que han dicho lo que en el aquí-ahora de la enunciación dice el narrador en su monodiálogo. Los marcadores lingüísticos "se dice" o "dicen" acentúan la dimensión oral del discurso. El narrador no asume la responsabilidad de lo que declara, pues asigna a otros los juicios y el origen de la historia.

\section{El monodiálogo como signo de la oralidad}

La categoría denominada monodiálogo es recuperada por Françoise Perus (2012) a partir de los trabajos de Ángel Rama y Carlos Pacheco; esta autora hace un balance, a la manera de una metacrítica, de los análisis que los investigadores y los críticos han planteado sobre la obra de Rulfo, especialmente respecto a la caracterización de los narradores. Su balance, y a la vez propuesta de análisis, aporta significativamente en dilucidar la zona más compleja de la obra artística de Rulfo: la constitución de sus narradores. Con la categoría monodiálogo se ubican los narradores que comunican sus historias a los narratarios representados explícitamente en el texto, es decir, cuando están presentes en el aquí-ahora del fluir narrativo, cuando escuchan in situ a los narradores: "Ya mirará usted ese viento que sopla sobre Luvina" es monodiálogo porque los narratarios nunca toman la palabra en el "diálogo", pero escuchan. Con la categoría narrador testigo se ubica a los narradores que han observado o han participado en la historia y en un tiempo posterior la recomponen: el narrador que está 
al lado del personaje, que en otro trabajo hemos llamado, siguiendo a Eduardo Serrano, narrador paradiegético; el narrador testigo recurre también al monodiálogo.

Para Perus, en Rulfo "la asunción de la oralidad atañe a la configuración misma del objeto de la representación artística y al valor ético-cognitivo" de su obra (2012, p. 68). En efecto, "la oralidad no se reduce a una mera cuestión de estilo, de ritmo o de entonación" sino que, a través de su funcionalidad estética, propicia un universo de ideas, imaginarios, creencias, sentimientos y conocimientos que el arte literario de Rulfo moviliza para comprender las singularidades de las comunidades periféricas; de otro modo sería muy difícil conocer en profundidad, desde dentro de la textualidad escrita impregnada de halos de oralidad, estas visiones sobre el mundo.

Entonces, la respiración oral en la escritura, por decirlo de algún modo, hace parte de los recursos estéticos del autor para hacer sentir unas representaciones imaginarias sobre la vida y la muerte; $y$ hacen parte también de la oralidad los versos de canciones populares y las frases acuñadas de procedencia religiosa y conversacional; también allí hay unas imágenes que refuerzan el propósito de la poética de Rulfo. En la cosmovisión, propiciada por la escritura límpida de Rulfo, sobresale la imagen del ser humano que peregrina y busca, porque la carencia lo empuja hacia el encuentro de lo que le falta para completarse, aunque lo buscado sea siempre la ilusión de una redención que se aleja a medida que se camina. Es aquí en donde se percibe el motivo literario de la orfandad. "El sentimiento de pérdida es una manifestación casi permanente en la novela y en los cuentos de Rulfo", anota Julio Estrada (1990, p. 28). Por eso, aunque con morosidad, los personajes caminan y sus historias quedan abiertas (en elipsis), aunquela narración se clausure.

\section{Conclusiones}

Es importante llamar la atención sobre afirmaciones taxativas respecto a la presencia de la oralidad en la obra de Rulfo; el proceso de enunciación de los narradores no es plenamente oral; si lo fuese no sería literatura sino transcripción sonora de lo que conversan y narran las personas en el campo o en los pueblos pequeños; no se trata tampoco de una transposición de conversaciones orales en la escritura literaria; si así fuera no habría verosimilitud, algo inherente a las obras de arte (ni es verdad ni es mentira, es verosímil).

La oralidad hace parte del material del escritor y como tal lo remodela y lo transforma, en un esfuerzo por hacer sentir los microuniversos culturales de una sociedad, dando lugar a la interpelación ideológica, la que el lector crítico ha de descubrir. Asunto distinto es proponer como hipótesis de trabajo el carácter subyacente de los tonos de la oralidad en la escritura literaria; hacer sentir que escuchamos y no que leemos, aunque es a través de la lectura que percibimos las voces, constituye el más alto valor estético y ético de Rulfo, porque solo así nos compenetramos con esos mundos para comprender sus complejidades.

\section{Reconocimientos}

El artículo presenta resultados de investigaciones adelantadas en torno al lenguaje, la literatura y la educación, y específicamente de "Palimpsestos: la literatura en el contexto escolar", respaldada por la Universidad Nacional de Colombia y la Universidad Autónoma de México. Los análisis han sido objeto de trabajo con docentes de educación básica en el marco de proyectos de formación pedagógica. 


\section{Bibliografía}

Ascencio, J. (2005). Un extraño en la tierra. Biografía no autorizada de Juan Rulfo. México: Mondadori.

Campbell, F. (2003). Selección y prólogo. En La ficción de la memoria. Juan Rulfo ante la crítica. México: UNAM-Era.

Estrada, J. (1990). El sonido en Rulfo. México: UNAM.

Figueroa, C. (1995). Señores vengo a contarles... México: Secretaría de Gobernación - Instituto Nacional de Estudios Históricos de la Revolución.

Garrido, F. (2004). Voces de la tierra. La lección de Juan Rulfo. México: UNAM.

Genette, G. (1972). Figures III. París: Éditions du Seuil.

Hjelmslev, L. (1972). Prolegómenos a una teoría del lenguaje. Madrid: Gredos.

Jakobson, R. (1973). Questions de Poétique. París: Du Seuil.

Jurado, F. (2005). Pedro Páramo, de Juan Rulfo. Murmullos, susurros y silencios. Bogotá: Común Presencia.

Jiménez, V. (2006). Palabra llana y poesía en Rulfo. En V. Jiménez, A. Vital y J. Zepeda, Tríptico para Juan Rulfo. Poesía, fotografía, crítica. México: Fundación Juan Rulfo, Editorial RM; Universidades Nacional Autónoma de México, Iberoamericana, De Colima, Autónoma de Aguascalientes.
Lienhard, M. (1992). La voz y su huella. México: Casa Juan Pablos.

López Mena, S. (2007). Diccionario de la obra de Juan Rulfo. México: UNAM.

Magdaleno, M. (1954). El ardiente verano. México: FCE.

Mendoza, V. (1954). El corrido mexicano. México: FCE.

Mignolo, W. (1992). Escribir la oralidad: la obra de Juan Rulfo en el contexto de las literaturas del “Tercer mundo". En Juan Rulfo: toda la obra. Unesco, Colección Archivos.

Pascual Buxó, J. (1992). Juan Rulfo: los laberintos de la memoria. En Juan Rulfo: toda la obra. Unesco, Colección Archivos.

Perus, F. (2012). Juan Rulfo, el arte de narrar. México: Fundación Juan Rulfo -Editorial RM; UNAM, UNAL, U. A. de Guerrero.

Rama, Á. (1974-1982). Los procesos de transculturación en la narrativa latinoamericana. En Rama. La novela latinoamericana, 1920-1980. Bogotá: Procultura.

Ortiz, F. (1963). Contrapunto cubano del tabaco y el azúcar. La Habana: Consejo Nacional de Cultura.

Pacheco, C. (1992). La comarca oral. La ficcionalización de la oralidad cultural en la narrativa latinoamericana contemporánea. Caracas: La Casa de Bello.

Rulfo, J. (1987). Obras. México: FCE.

Rulfo, J. (2005). Pedro Páramo. México: Fundación Juan Rulfo, Editorial RM. 
Rulfo, J. (2010). El gallo de oro. México: Fundación Juan Rulfo, Editorial RM.

Rulfo, J. (1994). Fray Bernardino de Sahagún. En Los cuadernos de Juan Rulfo. México: Era.
Vital, A. (1998). Juan Rulfo. México: Tercer Milenio.

Vital, A. (2012). Rilke, Rulfo. México: Samsara. 